\title{
Leadership Matters How to Help Principals Promote Teaching Effectiveness
}

Even though teachers influence student achievement more than any other aspect of schooling, those who manage the teachers-school principals-also play an important role by creating conditions that can support or hinder effective teaching. As schools and districts move toward performance-based teacher evaluation as a way to improve teaching effectiveness and student outcomes, the principal's role in teacher evaluations is becoming even more important.

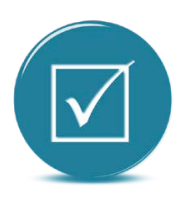

The growing emphasis on teacher evaluation suggests a need to change the ways principals are trained, supported, and evaluated.

Principals are responsible for evaluating teachers, and as managers, they influence how teacher evaluations are used to enhance teacher effectiveness. Many principals conduct classroom observations and rate teachers' performance or manage those who do. Most principals use this evaluation information when providing feedback to teachers and identifying professional learning opportunities to help them improve. Some principals also use evaluations to guide placement and other staffing decisions.

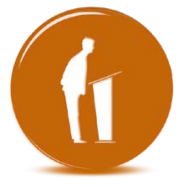

Principals need skills that enable them to evaluate and improve instruction, but many principals report feeling underequipped.

They report needing coaching to help them evaluate teachers effectively and then provide teachers with honest and actionable feedback to improve their performance. Principals may also need training on how to use evaluation data to make decisions about personnel actions and teachers' professional development.

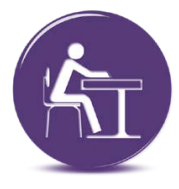

Principals need working conditions that facilitate their efforts to improve teaching.

Principals' working conditions influence their ability to help teachers continually improve. Two factors that appear to foster principals' success are decisionmaking authority over teacher hiring and professional development, and access to data systems and analysis tools that help principals provide concrete feedback to teachers.

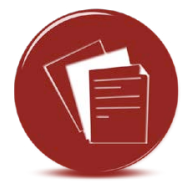

Principal evaluations should be aligned with teacher evaluations and reflect goals for improving instruction.

If teachers are held accountable for student outcomes, it stands to reason that principals should be as well. And if teachers are being evaluated on their instructional practices, such as classroom management or ability to individualize instruction, principals should be evaluated on how well they support the implementation of those instructional practices, for example, through targeted feedback and tailored professional development. 